\title{
EROSÃO HÍDRICA ASSOCIADA A ALGUMAS VARIÁVEIS HIDROLÓGICAS EM POMAR DE MAÇÃ SUBMETIDO A DIFERENTES MANEJOS DO SOLO ${ }^{(1)}$
}

\author{
Ederson Gobbi ${ }^{(2)}$, Ildegardis Bertol ${ }^{(3)}$, Fabrício Tondello \\ Barbosa $^{(4)}$, Romeu de Souza Werner ${ }^{(5)}$, Roger Robert Ramos ${ }^{(6)}$, \\ Jorge Paz-Ferreiro $^{(7)}$ \& Luciano Gebler ${ }^{(8)}$
}

\begin{abstract}
RESUMO
O manejo do solo em cultivos perenes, como pomares, influencia a erosão hídrica. $O$ presente estudo avaliou as perdas de solo e água sob chuva simulada em um Latossolo, em pomar de maçã, entre os meses de agosto de 2007 e abril de 2008, na estação experimental de fruticultura de clima temperado da Embrapa Uva e Vinho, em Vacaria (RS). O trabalho foi conduzido em parcelas experimentais de 3,5 x $11 \mathrm{~m}$, sob chuvas com $1 \mathrm{~h}$ de duração e intensidade constante ao longo delas, com variação de 70 a $88 \mathrm{~mm} \mathrm{~h}^{-1}$ entre uma chuva e outra. Os sistemas de manejo estudados foram: 1) capina manual sob a copa das plantas e solo coberto com gramíneas e leguminosas no restante da área (ST); 2) aveia não dessecada, em que as sementes foram incorporadas ao solo, com capina manual em toda a área, dois meses antes do início dos testes de chuva (AN); 3) aveia dessecada quimicamente sete dias antes do início dos testes de chuva, em que as sementes foram incorporadas ao solo com enxada rotativa em toda a área, dois meses antes do início dos testes (AD); e 4) solo sem cobertura, em que a vegetação, após ter sido dessecada, foi removida da superfície do solo em toda a área com capina manual, um dia antes de iniciar os testes de chuva (SC). A forma de manejo da superfície do solo e o número de chuvas influenciaram a erosão hídrica; as perdas de solo variaram amplamente, enquanto as perdas de água apresentaram menor variação. Apesar da mobilização do solo para implantação de aveia, os tratamentos AN e AD com
\end{abstract}

\footnotetext{
(1) Parte da Dissertação de Mestrado do primeiro autor. Recebido para publicação em abril de 2010 e aprovado em março de 2011.

(2) Mestrando em Manejo do Solo, Centro de Ciências Agroveterinárias - CAV, Universidade do Estado de Santa Catarina UDESC. Av. Luis de Camões 2090, CEP 88520-000 Lages (SC). E-mail: edermt2003@yahoo.com.br

(3) Professor de Uso e Conservação do Solo, CAV/UDESC. Bolsista do CNPq. E-mail: a2ib@cav.udesc.br

(4) Doutorando em Manejo do Solo, CAV/UDESC. E-mail: a6ftb@cav.udesc.br

(5) Bolsista de Iniciação Científica, CAV/UDESC. E-mail: a8rsw@cav.udesc.br

(6) Mestrando em Manejo do Solo, CAV/UDESC. E-mail: a6rrr@cav.udesc.br

(7) Facultad de Ciencias, Universidad da Coruña, La Coruña, Espanha. E-mail: jpaz@udc.es

(8) Pesquisador da Embrapa Uva e Vinho, Vacaria (RS). E-mail: lugebler@m2net.com.br
} 
esse cultivo mostraram a mesma eficácia de controle da erosão em relação ao tratamento ST, em que o solo foi mobilizado apenas sob a copa das plantas. A eliminação da cobertura do solo no tratamento SC aumentou expressivamente as perdas de solo em relação aos tratamentos com cobertura; no que se refere às perdas de água, a diferença foi menor. O tempo de ocorrência do escoamento superficial influenciou a perda de solo; observou-se aumento dessa variável com o aumento do tempo de enxurrada até certo momento, a partir do qual diminuiu, independentemente do tratamento; a perda de água aumentou até certo momento e estabilizou. Houve relação inversa entre razão de perda de solo e razão de perda de água, independentemente do tipo de cobertura do solo e do sistema de manejo sob as macieiras. O modelo exponencial ajustou-se a essa relação.

Termos de indexação: erosão em pomar, chuva simulada, hidrograma, sedimentograma.

\section{SUMMARY: WATER EROSION ASSOCIATED TO SOME HYDROLOGICAL VARIABLES IN APPLE ORCHARD UNDER DIFFERENT SOIL MANAGEMENTS}

Soil management in perennial crops such as orchards can influence erosion. This study evaluated soil and water losses from an Oxisol under simulated rain, from August 2007 to April 2008, at the experimental station of Embrapa Uva e Vinho, in Vacaria (RS). On the $3.5 \mathrm{~m} \times 11 \mathrm{~m}$ plots, rains of one hour were simulated at a constant intensity of 70 to $88 \mathrm{~mm} \mathrm{~h}^{-1}$. In the apple orchard, the following soil management systems were studied: i) manual weeding under apple trees and spontaneous grass and legume cover in the rest of the area (ST), ii) undesiccated oat cover, hoeing the seeds into the soil at weeding in the entire area, two months before the first rain test (NO), iii) oat cover chemically desiccated seven days before the first rain test, planted by a rotary hoe to incorporate seeds into the soil in the entire area, two months before the tests (DO); and iv) uncovered soil with removal of the previously desiccated spontaneous cover from the soil surface by weeding the entire area with a hoe, one day before each rain test (BS). The management systems related to the soil cover in the apple orchard and the rain tests influenced water erosion. Soil losses varied considerably in the treatments, more than water losses. Even with soil mobilization in the entire area for oat planting in the NO and DO treatments the control effectiveness of water erosion was equal to the ST treatment in which the soil was mobilized only under the trees. The removal of the soil cover from under apple trees greatly increased soil losses in relation to the cover maintenance, but had only little influence on water losses. The runoff duration influenced soil loss; an increase of this variable was observed with increasing runoff duration until a certain moment and, from then on, it decreased independently of the treatment; water loss increased until a certain moment and stabilized. An inverse relationship was observed between soil and water losses, independently of the soil management system under apple trees, adjusting to an exponential model.

Index terms: Erosion in orchard, simulated rainfall, hydrogram, sedimentgram.

\section{INTRODUÇÃO}

A área agrícola cultivada com maçã no Estado de Santa Catarina totaliza 16.800 ha, segundo a AMAP (2009), e 14.000 ha no Estado do Rio Grande do Sul, segundo a AGAPOMI (2007), com expressiva importância econômica para os dois Estados. Apesar da importância econômica dessa cultura, poucos estudos têm sido realizados no Brasil quanto ao aspecto de conservação do solo, em especial quanto à erosão hídrica, em sistemas de manejo do solo comumente adotados no cultivo de maçã. No passado recente, o manejo do solo, especialmente os tratos culturais em pomares de maçã, era realizado com o objetivo de maximizar a produção. Atualmente, objetiva-se também a melhoria da qualidade do produto final (maçã), além de fazer com que essa atividade altere o mínimo possível o meio ambiente (Marangoni et al., 1995).

Embora a erosão hídrica seja um problema amplamente reconhecido no mundo, existem grandes dificuldades para estimar sua magnitude e modelá-la (Renard et al., 1997), sobretudo quando ela ocorre em sistemas de manejo de solo envolvendo cultivos 
perenes, devido à falta de dados. Esses dados são imprescindíveis em estudos de modelagem de erosão e no planejamento de manejo do solo visando sua conservação.

Em geral, o preparo mecânico do solo para a implantação de pomares e o trânsito de máquinas durante a condução destes são intensos (O'Geen et al., 2006). Na implantação de pomares, são realizadas diversas operações mecânicas com subsolador, arado, grade e enxada rotativa, com o objetivo de preparar o terreno e incorporar corretivo e fertilizante ao solo, o que resulta em intensa mobilização de grande volume de solo (Penteado Júnior et al., 2008). Além disso, essas operações de preparo do solo são realizadas independentemente de orientação em relação à pendente do terreno, sendo, na maioria das vezes, morro abaixo. Preparos de solo excessivamente intensos resultam, em geral, em condições que predispõem o solo à elevada erosão hídrica, tanto em entre sulcos (Schäefer et al., 2001b; Cassol et al., 2004) quanto em sulcos (Schäefer et al., 2001a), resultando em erosão superficial acelerada, conforme observado por Cogo et al. (1984), Leite et al. (2004) e Bertol et al. $(2006,2008)$. Subsequentemente ao plantio da cultura, o manejo do solo é conduzido mantendo-se a zona da entrelinha das plantas coberta com vegetação. Além disso, utiliza-se tração mecânica nessa zona, visando às operações de aplicação de adubos e defensivos agrícolas, colheita e transporte das frutas (O'Geen et al., 2006; Penteado Júnior et al., 2008).

Em decorrência do inadequado sistema de manejo do solo, durante o seu preparo e imediatamente após a implantação do pomar, expressivas quantidades de solo são perdidas por erosão hídrica nessas áreas (Kosmas et al., 1997; Sanchez et al., 2002). Ao longo do tempo, a partir da fase de implantação dos pomares, o solo tende a tornar-se compactado na zona da entrelinha das plantas, principalmente devido ao efeito da pressão mecânica exercida pelo tráfego de máquinas (Woorhees \& Lindstrom, 1984; O'Geen et al., 2006). Com isso, diminui expressivamente a taxa de infiltração de água, e a erosão hídrica pluvial aumenta consideravelmente no pomar, especialmente as perdas de água (Gobbi, 2009).

A erosão hídrica pluvial é a principal responsável pelas perdas de água e solo ocasionadas por meio de enxurrada, sobretudo em áreas agrícolas (Hudson, 1995). Por isso, essa forma de erosão constitui-se em um dos principais fatores de empobrecimento do solo no local de origem da erosão e de contaminação do ambiente fora desse local. Essa contaminação é mais acentuada na água de superfície, especialmente nos mananciais de água doce, devido ao potencial que a enxurrada apresenta para transportar sedimentos coloidais e produtos químicos adsorvidos a tais sedimentos (Sharpley et al., 1987).

A avaliação quantitativa de erosão hídrica sob chuva natural é difícil, em especial em pomares, devido, nesse caso, às dificuldades inerentes à forma de manejo destes e à falta de mão de obra qualificada e disponível por longo prazo. Além disso, essa avaliação é custosa devido ao longo período de tempo no qual ela tem de ser feita para que os dados sejam confiáveis. Em razão disso, a quantificação de erosão hídrica nesses pomares por meio de chuva simulada é uma alternativa viável, ainda que trabalhosa, pois permite obter resultados confiáveis em curto prazo (Gobbi, 2009). Esses resultados - obtidos dessa forma em pomares de maçã, por exemplo - podem ser extrapolados com certa confiabilidade para outras culturas perenes implantadas em situações semelhantes às do experimento avaliado, uma vez que o sistema experimental é razoavelmente controlado no caso de chuva simulada. Assim, reveste-se de importância a quantificação de erosão hídrica pluvial do solo em áreas de pomares de maçã, por meio de chuva simulada.

O objetivo deste trabalho foi quantificar as perdas de água e solo por erosão hídrica associada a algumas variáveis hidrológicas, sob a aplicação de chuvas simuladas em pomar de maçã submetido a diversos sistemas de manejo do solo.

\section{MATERIAL E MÉTODOS}

O trabalho foi conduzido em um pomar de macieiras com 15 anos de idade, entre agosto de 2007 e abril de 2008, na estação experimental da Embrapa Uva e Vinho, unidade de Vacaria, no nordeste do Estado do Rio Grande do Sul (latitude $28^{\circ} 30$ ' S e longitude de $50^{\circ} 52$ ' W). As macieiras foram plantadas em 1992, com espaçamento de 2,5 × $5 \mathrm{~m}$, com linhas contornando a pendente, sobre um solo Latossolo Bruno aluminoférrico típico (Embrapa, 2006), com declividade suavemente ondulada no local do experimento. A composição granulométrica do solo, determinada por Curcio et al. (1999) em um perfil modal situado próximo da área experimental, encontra-se no quadro 1.

Estudaram-se quatro sistemas de manejo do solo no pomar, ambos em duas repetições, a seguir descritos: 1) capina manual sob as plantas e cobertura vegetal composta de gramíneas e de leguminosas no restante da área, denominado sistema tradicional (ST); 2) solo coberto com aveia não dessecada, em que as sementes foram incorporadas ao solo em toda a área por meio de enxada manual, dois meses antes do início dos testes de chuva (AN); 3) solo coberto com aveia, em que as sementes foram incorporadas mecanicamente ao solo em toda a área por meio de enxada rotativa, dois meses antes do início dos testes de chuva, cuja parte aérea foi dessecada quimicamente sete dias antes do início dos testes de chuva (AD); e 4) solo sem cobertura, em que a vegetação presente (gramíneas e leguminosas) foi dessecada quimicamente e removida da superfície do solo em toda a área por meio de enxada manual, um dia antes do início dos testes de chuva (SC). No tratamento ST, o volume de 
Quadro 1. Composição granulométrica do Latossolo Bruno aluminoférrico típico, localizado na estação experimental da Embrapa Uva e Vinho, em Vacaria

\begin{tabular}{|c|c|c|c|c|c|c|}
\hline Horizonte & Profundidade & $\mathbf{A G}$ & AF & SI & AR & ARDA \\
\hline Símbolo & $\mathrm{cm}$ & & & $\mathrm{g} \mathrm{kg}^{-1}$ & & \\
\hline $\mathrm{A} 1$ & $0-26$ & 25 & 35 & 274 & 666 & 229 \\
\hline $\mathrm{A} 2$ & $27-44$ & 31 & 21 & 241 & 707 & 478 \\
\hline $\mathrm{AB}$ & $45-65$ & 21 & 19 & 169 & 791 & 583 \\
\hline $\mathrm{BA}$ & $66-80$ & 17 & 12 & 159 & 812 & 520 \\
\hline Bw1 & $81-100$ & 21 & 14 & 155 & 810 & 0 \\
\hline Bw2 & $101-130$ & 21 & 19 & 148 & 812 & 0 \\
\hline Bw3 & $131-177$ & 25 & 21 & 142 & 812 & 0 \\
\hline Bw4 & $178-220+$ & 21 & 21 & 147 & 811 & 0 \\
\hline
\end{tabular}

AG: areia grossa; AF: areia fina; SI: silte; AR: argila; ARDA: argila dispersa em água.

macroporos era de $0,04 \mathrm{dm}^{3} \mathrm{dm}^{-3}$ na porção da superfície sem mobilização do solo. A mobilização do solo, feita sob as plantas de maçã para incorporar adubos neste tratamento, para incorporar sementes de aveia nos tratamentos AN e AD e para remover a vegetação no tratamento SC, aumentou a macroporosidade para $0,25 \mathrm{dm}^{3} \mathrm{dm}^{-3}$ na camada mobilizada. A profundidade de mobilização do solo variou de 3 a $5 \mathrm{~cm}$. No pomar, as plantas de maçã apresentavam altura de 2,5 m, em média. Devido ao fato de as plantas serem maiores do que a altura dos braços do simulador de chuvas $(2,2 \mathrm{~m})$, elas foram podadas em $0,4 \mathrm{~m}$ na sua parte superior, para ficarem com a altura inferior à dos braços do simulador. Possivelmente, esse procedimento influenciou a erosão hídrica em relação à condição do pomar sem a poda, embora, talvez, fracamente.

A unidade experimental foi constituída de uma parcela com 3,5 m de largura por $11 \mathrm{~m}$ de comprimento no sentido do declive principal $\left(38,5 \mathrm{~m}^{2}\right)$, a qual foi instalada conforme Bertol et al. (1987). Utilizaram-se oito parcelas e, na aplicação das chuvas simuladas, foi usado um simulador de chuvas de braços rotativos (Figura 1), que cobria simultaneamente duas parcelas (Swanson, 1965), as quais eram repetições dos tratamentos.

Durante parte do ciclo vegetativo da cultura de maçã (entre setembro e dezembro de 2007), aplicaram-se três testes de chuva simulada em cada tratamento, com quatro chuvas cada teste (uma chuva em cada tratamento por teste), totalizando 12 chuvas. No período de aplicação das chuvas simuladas ocorreram algumas chuvas naturais. As características e as datas de aplicação das chuvas simuladas e a altura e intervalo de ocorrência das chuvas naturais constam no quadro 2.

No dia anterior aos testes 1, 2 e 3 de chuva simulada, determinou-se a cobertura do solo ocasionada pela cultura da aveia nos tratamentos $\mathrm{AN}$ e $\mathrm{AD}$ e pela vegetação de gramíneas e leguminosas no tratamento ST. Nessas determinações utilizou-se o procedimento do "metro rígido" descrito por Adams \& Arkin
(1977). Nesses mesmos dias, foi determinada também a cobertura do solo pela copa das plantas de maçã, de modo semelhante ao método descrito por Arruda (1984). Imediatamente antes da aplicação de cada uma das chuvas, coletou-se amostra de solo deformada, com auxílio de um trado tipo holandês na profundidade de 0-10 cm, em um ponto em cada parcela; posteriormente, nessas amostras determinou-se o teor de água no solo, gravimetricamente, conforme Forsythe (1975). Os valores dessas três variáveis encontram-se no quadro 3.

Durante os testes de chuva, foi registrado o tempo de início do escoamento superficial. Esse tempo referese ao intervalo entre o momento de início da chuva e o momento de chegada do fluxo na extremidade inferior do cano onde, em uma trincheira, coletavam-se as amostras de enxurrada. Esse cano ligava a extremidade inferior da calha coletora de enxurrada (situada na parte inferior da parcela experimental) e a trincheira de coleta de amostras de enxurrada

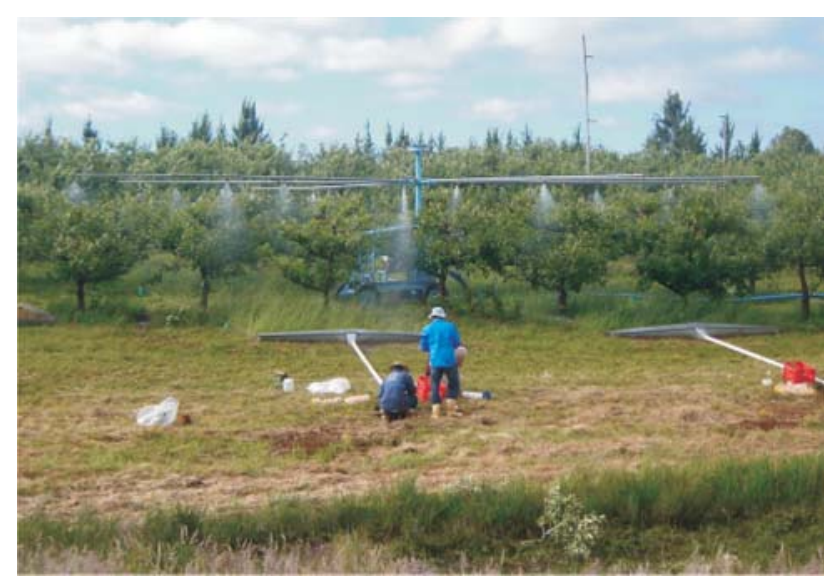

Figura 1. Simulador de chuva em operação no pomar de maçã sobre um Latossolo Bruno aluminoférrico típico, localizado na estação experimental da Embrapa Uva e Vinho de Vacaria. 
Quadro 2. Intensidade e altura de chuva simulada aplicada com uma hora de duração e altura e intervalo de ocorrência de chuva natural precipitada entre os testes de chuva simulada, no Latossolo Bruno aluminoférrico típico, localizado na estação experimental da Embrapa Uva e Vinho de Vacaria

\begin{tabular}{|c|c|c|c|c|}
\hline \multirow[b]{2}{*}{ Tratamento } & \multicolumn{4}{|c|}{ Chuva simulada: intensidade e altura } \\
\hline & $\begin{array}{c}\text { Teste } 1 \\
(27 / 10 / 2007)\end{array}$ & $\begin{array}{c}\text { Teste } 2 \\
(12 / 11 / 2007)\end{array}$ & \multirow[t]{2}{*}{$\begin{array}{c}\text { Teste } 3 \\
(27 / 11 / 2007)\end{array}$} & \multirow[t]{2}{*}{ Média } \\
\hline & & $\mathrm{mm} \mathrm{h}^{-1}$ e $\mathrm{mm}$ & & \\
\hline ST & 70 & 83 & 78 & 77 \\
\hline $\mathrm{AN}$ & 74 & 77 & 77 & 76 \\
\hline $\mathrm{AD}$ & 80 & 74 & 76 & 77 \\
\hline \multirow[t]{2}{*}{$\mathrm{SC}$} & 88 & 84 & 76 & 83 \\
\hline & \multicolumn{3}{|c|}{ Chuva natural: momento de ocorrência - altura } & \\
\hline Nos cinco dias antes do teste $1=0$ & $\begin{array}{l}\text { Entre o teste } 1 \text { e o } \\
\text { teste } 2=15 \mathrm{~mm}\end{array}$ & $\begin{array}{l}\text { Entre o teste } 2 \text { e o } \\
\text { teste } 3=45 \mathrm{~mm}\end{array}$ & $\begin{array}{l}\text { No tota } \\
\text { período }\end{array}$ & \\
\hline
\end{tabular}

ST: sistema tradicional; AN: aveia não dessecada; AD: aveia dessecada; SC: solo sem cobertura.

Quadro 3. Cobertura do solo pela copa das plantas de maçã, pela aveia e pelas gramíneas e leguminosas, e teor de água no solo, imediatamente antes dos testes de chuva simulada no Latossolo Bruno aluminoférrico típico, localizado na estação experimental da Embrapa Uva e Vinho de Vacaria

\begin{tabular}{|c|c|c|c|c|}
\hline Variável & Tratamento & Antes do teste 1 & Antes do teste 2 & Antes do teste 3 \\
\hline Copa das plantas de maçã $\left(\mathrm{m}^{2} \mathrm{~m}^{-2}\right)$ & $\begin{array}{l}\text { ST } \\
\text { AN } \\
\text { AD } \\
\text { SC }\end{array}$ & $\begin{array}{l}0,24 \\
0,22 \\
0,20 \\
0,18\end{array}$ & $\begin{array}{l}0,25 \\
0,25 \\
0,22 \\
0,21\end{array}$ & $\begin{array}{l}0,28 \\
0,28 \\
0,25 \\
0,25\end{array}$ \\
\hline $\begin{array}{l}\text { Aveia, gramíneas e leguminosas } \\
\qquad\left(\mathrm{m}^{2} \mathrm{~m}^{-2}\right)\end{array}$ & $\begin{array}{l}\mathrm{ST} \\
\mathrm{AN} \\
\mathrm{AD} \\
\mathrm{SC}\end{array}$ & $\begin{array}{l}0,56 \\
0,46 \\
0,41 \\
0,00\end{array}$ & $\begin{array}{l}0,55 \\
0,89 \\
0,52 \\
0,00\end{array}$ & $\begin{array}{l}0,55 \\
0,95 \\
0,30 \\
0,00\end{array}$ \\
\hline $\begin{array}{l}\text { Teor de água no solo na camada de } \\
\qquad \begin{array}{c}0,1 \mathrm{~m} \\
\left(\mathrm{~g} \mathrm{~g}^{-1}\right)\end{array}\end{array}$ & $\begin{array}{l}\mathrm{ST} \\
\mathrm{AN} \\
\mathrm{AD} \\
\mathrm{SC}\end{array}$ & $\begin{array}{l}0,33 \\
0,37 \\
0,46 \\
0,46\end{array}$ & $\begin{array}{l}0,31 \\
0,41 \\
0,37 \\
0,47\end{array}$ & $\begin{array}{l}0,36 \\
0,36 \\
0,41 \\
0,47\end{array}$ \\
\hline
\end{tabular}

ST: sistema tradicional; AN: aveia não dessecada; AD: aveia dessecada; SC: solo sem cobertura.

situada $6 \mathrm{~m}$ abaixo da extremidade inferior da parcela (Figura 1). Durante os testes de chuva, amostrou-se a enxurrada e mediu-se a taxa de descarga a partir do seu início, em intervalos fixos de 3 min durante a ocorrência desta, medindo-se também a lâmina de chuva precipitada.

Com os dados de enxurrada, determinou-se a perda de solo instantânea até o final da chuva (aos $60 \mathrm{~min}$ ), com a qual se confeccionou o sedimentograma, e calculou-se a perda total de solo. Com os dados de taxa de descarga, determinou-se a perda instantânea de água até o final do escoamento superficial (aos $66 \mathrm{~min}$ ), com a qual confeccionou-se o hidrograma, e calculou-se a perda total de água. Os cálculos foram realizados utilizando um programa computacional, do tipo planilha Excel, elaborado pelo Prof. Elemar Antonino Cassol do DS-FA-UFRGS, denominado
"PODEROSÃO", o qual não encontra-se publicado. Os dados obtidos de 3 em 3 min foram interpolados linearmente, resultando nas perdas instantâneas (de 1 em $1 \mathrm{~min}$ ) de sedimentos e de água. Com os dados de lâmina de chuva precipitada e lâmina de escoamento superficial, posteriormente calculou-se a lâmina de infiltração de água no solo. A relação entre a altura de enxurrada e a altura de chuva resultou no coeficiente de escoamento. A relação entre taxa de enxurrada e taxa de chuva resultou na razão de perda de água. A razão de perda de solo resultou da relação entre a perda de solo em um tratamento coberto e a perda de solo no tratamento descoberto. As amostragens e determinações basearam-se em Bertol et al. (1987). Os dados de perdas de solo observados foram ajustados para a declividade média das parcelas experimentais, que foi de $9,3 \mathrm{~cm} \mathrm{~m}^{-1}$, devido à variação 
de declividade do terreno entre um tratamento e outro (ST: $8,3 \mathrm{~cm} \mathrm{~m}^{-1}$, AN: $9,4 \mathrm{~cm} \mathrm{~m}^{-1}$, AD: $9,8 \mathrm{~cm} \mathrm{~m}^{-1}$ e SC: $9,7 \mathrm{~cm} \mathrm{~m}^{-1}$ ), utilizando o procedimento recomendado por Wischmeier \& Smith (1978), pela seguinte expressão:

$$
\mathrm{S}=0,065+4,56 \operatorname{sen} \theta+65,41(\operatorname{sen} \theta)^{2}
$$

em que $\theta=$ o ângulo do declive; e $\mathrm{S}=$ fator grau do declive (adimensional).

Devido à variação ocorrida na intensidade das chuvas simuladas aplicadas, entre uma chuva e outra (Quadro 2), as perdas de solo foram ajustadas para a intensidade de chuva planejada, conforme proposto por Cogo (1981), após ter sido feito o ajuste das perdas de solo para a inclinação das parcelas; no caso, a intensidade planejada foi de $70 \mathrm{~mm} \mathrm{~h}^{-1}$.

Os dados de perdas de água e solo foram submetidos à análise de variância; as comparações múltiplas de médias realizaram-se por contraste ortogonal. Quando houve interação entre o sistema de manejo e o teste de chuva, realizaram-se contrastes entre manejos em cada teste e entre testes dentro de cada manejo. Quando não houve interação, realizou-se contraste isolado em cada fator (manejo e teste). Ainda, realizouse regressão não linear entre a razão de perda de solo e a razão de perda de água para os três tratamentos com solo coberto sob as macieiras.

\section{RESULTADOS E DISCUSSÃO}

\section{Perda de água por escoamento superficial}

A perda de água por escoamento superficial iniciouse antes dos 15 min a partir do começo da chuva, com exceção do tratamento ST no teste 1 (Figura 2). Esse intervalo de tempo para o início de escoamento variou com o manejo do solo sob as plantas de maçã e com o teste de chuva, podendo ser considerado pequeno. $\mathrm{O}$ curto intervalo de tempo para início do escoamento superficial explica-se, em parte, pelo curto comprimento de rampa das parcelas experimentais (11 m) e pela elevada intensidade das chuvas simuladas aplicadas. Os tempos de início do escoamento variaram de 2,5 min (teste 2 - tratamento $A N$ ) a 18 min (teste 1 - tratamento ST), mostrando a influência do manejo do solo, da intensidade da chuva e do teor de água no solo antecedente à chuva sobre essa variável. Trabalhando na ausência de resíduos vegetais, sob diversos tipos de preparo do solo, Cogo et al. (1984) obtiveram tempos de início de escoamento superficial variando de 3 a $37 \mathrm{~min}$, em solo Hapludalfs típico nos EUA. Levien (1988) obteve tempos de início de escoamento superficial variando entre 3 e $>60 \mathrm{~min}$, trabalhando em um Argissolo cultivado com milho sob diversos sistemas de preparo e testes de chuva simulada. Tempos de início de escoamento superficial

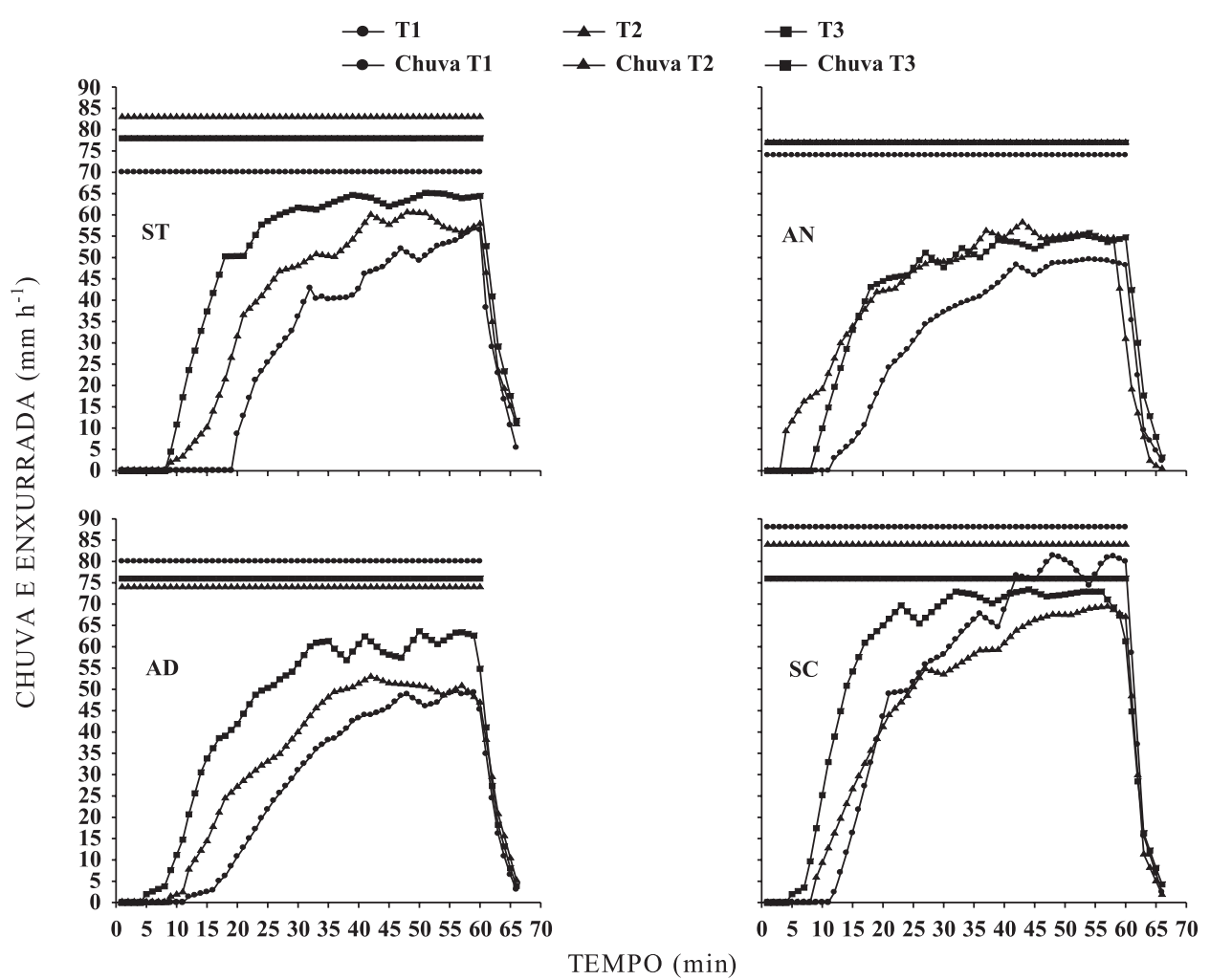

Figura 2. Hidrograma de chuva simulada realizada em sistemas de manejo do solo em pomar de maçã, sobre um Latossolo Bruno aluminoférrico típico, localizado na estação experimental da Embrapa Uva e Vinho de Vacaria. (Média das repetições). ST: sistema tradicional; AN: aveia não dessecada; AD: aveia dessecada; SC: solo sem cobertura; T1, T2 e T3: testes 1, 2 e 3 de chuva, respectivamente. 
variando entre 18 e 27 min foram obtidos por Bertol et al. (2006) no cultivo de soja, e entre 15 e 30 min por Bertol et al. (2008) nos cultivos de milho, feijão e soja, ambos sob diversos sistemas de manejo e chuva simulada em um Nitossolo Háplico. A elevada densidade do solo na área não mobilizada do pomar $\left(1,45 \mathrm{~kg} \mathrm{dm}^{-3}\right)$, observada por Gobbi (2009), também contribuiu para diminuir o tempo de início de escoamento, pois concorreu para dificultar a taxa de infiltração de água no solo (Quadro 4). No tratamento $\mathrm{AN}$, o escoamento superficial iniciou-se antes dos $5 \mathrm{~min}$ no teste 2 , enquanto nos tratamentos $\mathrm{AD}$ e $\mathrm{SC}$ isso ocorreu no teste 3 . Isso se explica principalmente pela mobilização do solo por ocasião da semeadura de aveia no caso de $\mathrm{AN}$ e $\mathrm{AD}$ e, no caso de SC, também pela ausência de cobertura na superfície do solo. Além disso, no SC ocorreu selamento na superfície do solo (observado visualmente pelos autores), em decorrência do impacto direto das gotas sobre a superfície descoberta. Em lavouras, onde o comprimento de rampa é maior do que o das parcelas utilizadas neste trabalho, é lícito esperar que o escoamento superficial demore mais tempo para percorrer a extensão total da lavoura do que em uma parcela experimental.

O tempo de pico do escoamento superficial, também denominado de tempo de equilíbrio da área, foi influenciado pelo manejo do solo sob as plantas de maçã, pelo teste de chuva e pela intensidade de chuva aplicada (Figura 2). Essa variável é uma importante

Quadro 4. Infiltração de água no solo, escoamento superficial e coeficiente de escoamento, em sistemas de manejo do solo em pomar de maçã, sobre um Latossolo Bruno aluminoférrico típico, localizado na estação experimental da Embrapa Uva e Vinho de Vacaria

\begin{tabular}{|c|c|c|c|c|}
\hline \multirow{2}{*}{ Teste de chuva } & \multicolumn{4}{|c|}{ Tratamento } \\
\hline & ST & $\mathrm{AN}$ & $\mathrm{AD}$ & SC \\
\hline & \multicolumn{4}{|c|}{ Infiltração de água no solo (mm) } \\
\hline Teste 1 & 31 & 39 & 48 & 32 \\
\hline Teste 2 & 40 & 35 & 37 & 36 \\
\hline Teste 3 & 26 & 33 & 29 & 17 \\
\hline \multirow[t]{2}{*}{ Média } & 32 & 36 & 38 & 28 \\
\hline & \multicolumn{4}{|c|}{ Escoamento superficial (mm) } \\
\hline Teste 1 & 39 & 35 & 32 & 40 \\
\hline Teste 2 & 43 & 42 & 37 & 36 \\
\hline Teste 3 & 52 & 44 & 47 & 59 \\
\hline \multirow[t]{2}{*}{ Média } & 45 & 40 & 39 & 45 \\
\hline & \multicolumn{4}{|c|}{ Coeficiente de escoamento } \\
\hline Teste 1 & 0,56 & 0,47 & 0,40 & 0,45 \\
\hline Teste 2 & 0,52 & 0,55 & 0,50 & 0,43 \\
\hline Teste 3 & 0,67 & 0,57 & 0,62 & 0,78 \\
\hline Média & 0,58 & 0,53 & 0,51 & 0,54 \\
\hline
\end{tabular}

ST: sistema tradicional; $\mathrm{AN}$ : aveia não dessecada; $\mathrm{AD}$ : aveia dessecada; SC: solo sem cobertura. característica do hidrograma, pois no momento de pico ocorre a taxa máxima de escoamento, a qual é indispensável para o planejamento de obras hidráulicas de drenagem. Em áreas agrícolas, essa informação é utilizada para o planejamento de terraços de drenagem. Leite et al. (2004), trabalhando em um Nitossolo Háplico, obtiveram tempos de pico de escoamento superficial variando de 22 a $71 \mathrm{~min}$, em diversos sistemas de manejo do solo e testes de chuva simulada sob os cultivos de milho e feijão. Tempos de equilíbrio variando entre 30 e 45 min foram encontrados por Bertol et al. (2008).

A observação visual da inclinação das curvas de taxa de escoamento superficial permite que se tenha uma ideia da taxa de aumento dessa variável hidrológica ao longo do tempo de duração do escoamento (Figura 2). Nesta figura, o crescimento da taxa de escoamento pode ser visualizado comparando os valores entre o tempo de início do escoamento e os tempos de aproximadamente $20 \mathrm{~min}$ no SC e $30 \mathrm{~min}$ nos demais tratamentos. O aumento da taxa de escoamento ocorreu rapidamente nos diversos tratamentos, distinguindo-se o SC, em que ela aumentou mais rapidamente do que nos demais, até o tempo de $20 \mathrm{~min}$. O SC claramente apresentava condições menos favoráveis para controle do escoamento superficial, permitindo o aumento mais acelerado dessa variável hidrológica. Isso ocorreu pelo fato de este tratamento não apresentar cobertura em superfície, o que fez com que a água escoasse mais livremente, sem obstáculo mecânico, do que nos demais tratamentos. Além disso, a ausência de cobertura no SC permitiu que o solo se degradasse fisicamente na superfície, provavelmente, mais do que nos demais tratamentos, nos quais o solo encontrava-se coberto. Os tratamentos ST, AN e $\mathrm{AD}$ apresentaram crescimento semelhante da taxa de escoamento entre si até o tempo de $30 \mathrm{~min}$, demonstrando não ter havido influência do manejo superficial do solo nesses tratamentos, sobre essa variável hidrológica, nesse intervalo de tempo. Portanto, esses três tipos de cobertura do solo apresentaram-se praticamente iguais no que refere-se ao crescimento da taxa de escoamento superficial nesse tempo de duração do escoamento. Bertol et al. (2008) também observaram aumento da taxa de escoamento superficial mais acentuado no solo descoberto do que em tratamentos com cultivo - fato esse observado também por Luciano et al. (2009) trabalhando em um Cambissolo Húmico.

A taxa máxima de enxurrada foi alta em relação à taxa de chuva aplicada e influenciada pelos tratamentos de manejo do solo e testes de chuva. A referida taxa variou de 52 a $61 \mathrm{~mm} \mathrm{~h}^{-1}$ no tratamento ST; de 50 a $55 \mathrm{~mm} \mathrm{~h}^{-1}$ no AN; no tratamento AD a variação foi de 48 a $64 \mathrm{~mm} \mathrm{~h}^{-1}$; e foi de 69 a $82 \mathrm{~mm} \mathrm{~h}^{-1}$ no SC (Figura 2). No tratamento ST, o solo apresentava baixo volume de macroporos $\left(0,04 \mathrm{dm}^{3} \mathrm{dm}^{-3}\right)$ e estava coberto na área não mobilizada, enquanto, na área mobilizada, a superfície estava descoberta; neste tratamento a intensidade das chuvas variou entre 70 
e $83 \mathrm{~mm} \mathrm{~h}^{-1}$ (Quadro 2). Nos tratamentos AN e AD houve mobilização do solo para a implantação da aveia em toda a parcela, o que aumentou a macroporosidade superficial do solo para $0,25 \mathrm{dm}^{3} \mathrm{dm}^{-3}$ nessa camada. Além disso, nestes tratamentos, a intensidade das chuvas variou entre 74 e $77 \mathrm{~mm} \mathrm{~h}^{-1}$ no AN e entre 74 e $80 \mathrm{~mm} \mathrm{~h}^{-1}$ no AD. No tratamento SC, além de o solo estar descoberto e mobilizado, a intensidade da chuva variou entre 76 e $88 \mathrm{~mm} \mathrm{~h}^{-1}$. Expressivas diferenças de taxa constante de enxurrada foram obtidas entre tratamentos de manejo e cultivo do solo também por Levien (1988), Leite et al. (2004), Bertol et al. (2006, 2008) e Luciano et al. (2009).

A infiltração de água no solo (Quadro 4) foi relativamente baixa comparada com a altura de chuva aplicada (Quadro 2), com variação de valores entre os tratamentos de manejo do solo e testes de chuva: entre $17 \mathrm{~mm} \mathrm{~h}^{-1}$ (teste 3 - tratamento SC) e $48 \mathrm{~mm} \mathrm{~h}^{-1}$ (teste 1 - tratamento $\mathrm{AD}$ ). Essa variação é normal, de acordo com a variação do escoamento superficial, sendo, principalmente, também influenciada pela interceptação e armazenagem superficial de água em função da variação de tipo de cobertura vegetal e da consolidação da superfície do solo sob as plantas de maçã, conforme verificado por Schäefer et al. (2001b) em trabalho usando microssimulador de chuvas sobre microparcelas de cultivos anuais sob semeadura direta. Nesse trabalho, os autores detectaram baixa taxa de infiltração de água no solo nos tratamentos recém-referidos. Sabidamente, a infiltração de água no solo é o principal processo do ciclo hidrológico em comparação com os demais processos que compõem o ciclo todo, do ponto de vista de conservação do solo, pois ela comanda o escoamento superficial e a forma do hidrograma (Schwab et al., 1993).

O volume de escoamento superficial (Quadro 4) foi relativamente alto comparado com a altura de chuva (Quadro 2), variando entre $32 \mathrm{~mm} \mathrm{~h}^{-1}$ (teste 1 tratamento $\mathrm{AD}$ ) e $59 \mathrm{~mm} \mathrm{~h}^{-1}$ (teste 3 - tratamento SC). Essa variação também foi normal e influenciada principalmente pela infiltração e, consequentemente, pelos mesmos fatores que a alteraram durante os eventos de chuva, conforme verificado também por O'Geen et al. (2006). Esses resultados contrariam alguns outros que mostram elevada taxa de infiltração de água, como os encontrados por Schäefer et al. (2001) em Argissolo e Vieira \& Klein (2007) em Latossolos. Elevados volumes de escoamento superficial justificam a preocupação com a adoção de medidas de contenção de escoamento, mesmo em sistema de cultivo perene, como é o caso de pomar de maçã. Em geral, em experimentos dessa natureza as perdas de água são elevadas em relação à altura de chuva, sobretudo quando conduzidos sob chuva crítica, como constatado por Leite et al. (2004), Bertol et al. (2008) e Luciano et al. (2009). Assim, a implantação de práticas de suporte de conservação do solo nesse tipo de cultivo é justificável (Wischmeier \& Smith, 1978), as quais devem ser planejadas e implantadas antes da implantação do pomar.
A razão entre taxa de escoamento e taxa de chuva no tempo de pico do escoamento superficial é expressa como o coeficiente de escoamento. Esse coeficiente variou entre 0,40 (teste 1 - tratamento $A D$ ) e 0,78 (teste 3 - tratamento SC) e foi determinado com base em chuva crítica, ou seja, chuva com intensidade e altura suficiente para fazer com que a área efetivamente atingisse o equilíbrio em termos de escoamento superficial. Isso significa que no tempo de equilíbrio a taxa de escoamento superficial representava $40 \%$ da taxa de chuva no solo coberto com aveia dessecada (AD) e $78 \%$ no solo sem cobertura sob as macieiras. A taxa máxima de escoamento ocorrente a partir do tempo de equilíbrio de uma área qualquer é o atributo hidrológico fundamental no planejamento de obras hidráulicas destinadas à drenagem de água para fora da área de interesse - no presente caso, para fora do pomar. Ampla variação de coeficiente de escoamento entre sistemas de manejo do solo foi observada também por Bertol et al. (2006, 2008).

O volume de água escoada variou estatisticamente, tendo o tratamento SC apresentado perda maior do que os demais, os quais não variaram entre si (Quadro 5). A igualdade dos dados nos tratamentos com cobertura do solo deveu-se, possivelmente, à pequena variação do tempo de início e da taxa máxima de escoamento e da semelhante velocidade de aumento do escoamento ao longo do tempo (Figura 2). A capacidade de infiltração de água no solo, limitada por suas características intrínsecas, conforme

Quadro 5. Contraste de médias das perdas de água por escoamento superficial, em sistemas de manejo do solo em pomar de maçã, sobre um Latossolo Bruno aluminoférrico típico, localizado na estação experimental da Embrapa Uva e Vinho de Vacaria

\begin{tabular}{|c|c|}
\hline Sistema de manejo & Perda de água ( $\%$ da chuva) \\
\hline $\mathrm{SC}$ & 66 \\
\hline $\mathrm{ST}$ & 58 \\
\hline AN & 53 \\
\hline $\mathrm{AD}$ & 50 \\
\hline \multicolumn{2}{|l|}{ Contraste } \\
\hline $\mathrm{SC}$ vs (ST, $\mathrm{AN}, \mathrm{AD})$ & $* *$ \\
\hline $\mathrm{ST}$ us $(\mathrm{AN}, \mathrm{AD})$ & $\mathrm{ns}$ \\
\hline $\mathrm{AN} v s \mathrm{AD}$ & $\mathrm{ns}$ \\
\hline Teste & Perda de água ( $\%$ da chuva) \\
\hline $\mathrm{T} 1$ & 49 \\
\hline $\mathrm{T} 2$ & 50 \\
\hline T3 & 61 \\
\hline \multicolumn{2}{|l|}{ Contraste } \\
\hline $\mathrm{T} 1$ vs (T2, T3) & $\mathrm{ns}$ \\
\hline $\mathrm{T} 2$ vs $\mathrm{T} 3$ & $* *$ \\
\hline
\end{tabular}

ST: sistema tradicional; AN: aveia não dessecada; AD: aveia dessecada; SC: solo sem cobertura; T1: teste 1; T2: teste 2; T3: teste 3 . Ns: não significativo pelo teste $\mathrm{F}$; **: significativo a $1 \%$ pelo teste F. Sem interação entre manejo e teste. 
argumentado por Kohnke (1968), explica em parte essa igualdade entre tratamentos. Isso também foi influenciado pelo fato de que os dados do quadro 5 representam a média dos testes de chuva, distintamente dos dados apresentados no quadro 4. A ausência de cobertura do solo sob as plantas de maçã no SC explica a maior perda de água ocorrida neste tratamento em relação aos demais. Dos tratamentos com cobertura do solo, o AD apresentou eficiência no controle do escoamento de $48 \%$, enquanto o ST de $64 \%$, embora sem diferença estatística. Entre os tratamentos cultivados com aveia sob as plantas de maçã ( $\mathrm{AD}$ e $\mathrm{AN})$, as perdas de água apresentaram valores semelhantes. Isso mostra que o manejo da aveia sob as plantas de maçã não influenciou as características de superfície do solo a ponto de alterar o volume de escoamento.

As perdas de água no teste 3 foram superiores estatisticamente àquelas ocorridas nos demais testes, na média dos tratamentos (Quadro 5), influenciadas pelo menor tempo de início e, principalmente, pelo mais rápido aumento da taxa de escoamento superficial. Em alguns casos, a maior taxa constante de escoamento também influenciou, em relação aos demais testes.

\section{Perda de solo por erosão hídrica}

A perda de solo aumentou mais rapidamente e atingiu valor mais alto no tratamento SC do que nos demais, principalmente no teste 1 de chuva (Figura 3), variando entre os testes especialmente no tratamento SC. No caso deste tratamento, essa perda atingiu o valor máximo de $10,5 \mathrm{~kg} \mathrm{~m}^{-3}$ aos 39 min de chuva no teste 1 , enquanto no teste 2 a referida perda atingiu o pico de $3,4 \mathrm{~kg} \mathrm{~m}^{-3}$ aos $24 \mathrm{~min}$ e, no teste 3 , o pico foi de $3,6 \mathrm{~kg} \mathrm{~m}^{-3}$ aos $41 \mathrm{~min}$ de chuva. A perda de solo no teste 1 do tratamento SC mostrou expressiva variação ao longo da chuva. Para os demais (ST, AN e $\mathrm{AD}$ ), os valores de perda de solo situaram-se em geral abaixo de $1 \mathrm{~kg} \mathrm{~m}^{-3}$ ao longo do tempo, em especial nos testes 2 e 3 de chuva, nos quais essas perdas foram da ordem de $0,5 \mathrm{~kg} \mathrm{~m}^{-3}$, praticamente sem variação ao longo do tempo. Esses dados refletem o efeito do manejo do solo e da sequência de chuvas sobre a perda de solo, conforme constatado também por Kosmas et al. (1997), Schäefer et al. (2001b), Sanchez et al. (2002), Cassol et al. (2004) e Luciano et al. (2009). O tratamento menos eficaz no controle da erosão, o SC, assim se comportou devido à ausência de cobertura do solo sob as plantas de maçã. Ainda, isso foi influenciado pela operação de capina manual efetuada para a retirada dessa cobertura (Material e Métodos), o que ocasionou a desagregação do solo. Assim, esse solo tornou-se prontamente disponível ao transporte pelo escoamento superficial, o que ocasionou nele elevada concentração de sedimentos, sobretudo no teste 1 de chuva. Essa concentração diminuiu nos testes posteriores, quando a maior parte desses sedimentos já havia sido removida. Nos tratamentos com cobertura de solo (ST, AN e AD), a perda de solo foi baixa. Isso reafirma o efeito positivo da cobertura do solo, tanto por

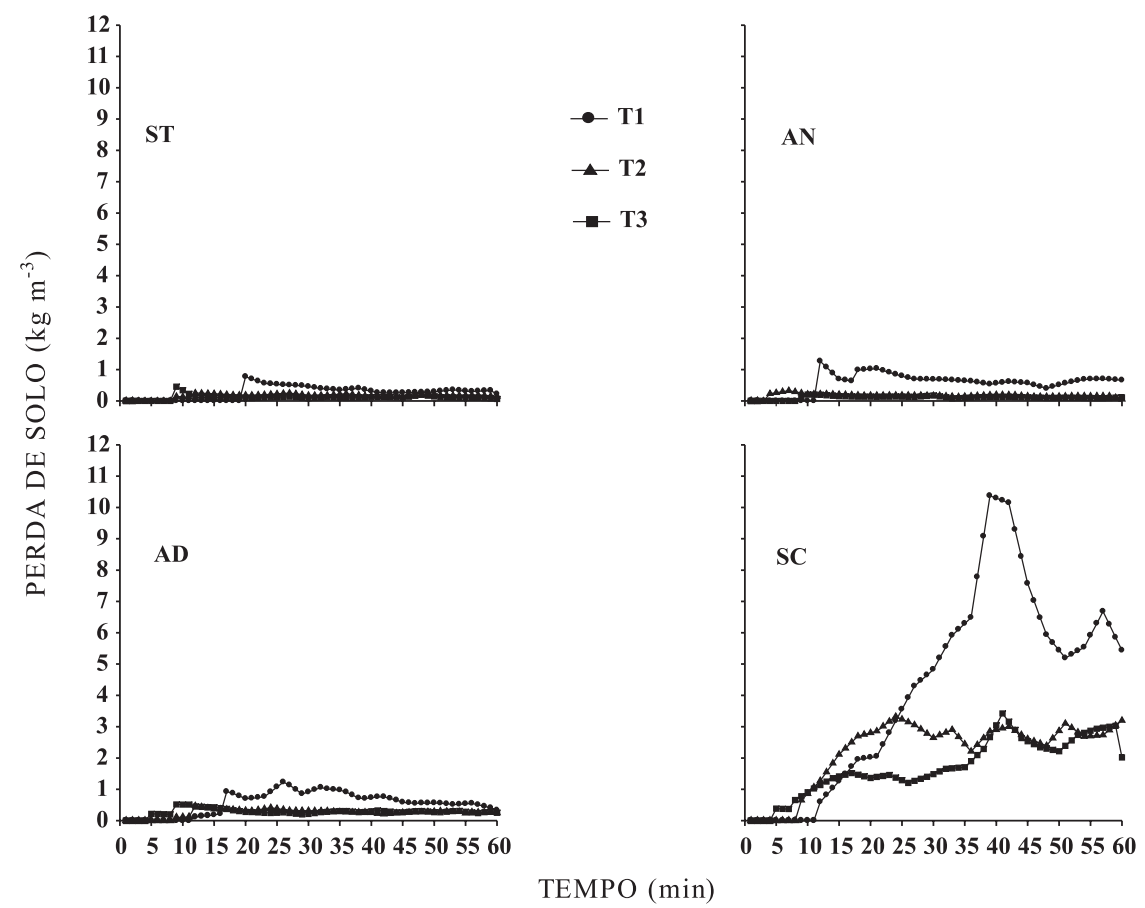

Figura 3. Sedimentograma de chuva simulada realizada em sistemas de manejo do solo em pomar de maçã, sobre um Latossolo Bruno aluminoférrico típico, localizado na estação experimental da Embrapa Uva e Vinho de Vacaria. (Média das repetições). ST: sistema tradicional; AN: aveia não dessecada; AD: aveia dessecada; SC: solo sem cobertura; T1: teste 1; T2: teste; e T3: teste 3. 
gramíneas solteiras quanto pelo consórcio de gramíneas e leguminosas, no controle das perdas de solo por erosão, conforme constatado por Luciano et al. (2009).

O tratamento $\mathrm{SC}$ apresentou perdas de solo significativamente maiores do que aqueles com algum tipo de cobertura do solo (ST, AN e AD), em todos os testes de chuva simulada (Quadro 6). Comparando esses três tratamentos com cobertura do solo, constatase que não houve diferença estatística entre eles para as perdas totais de solo. Explica-se esse comportamento pelo efeito combinado dos dados recém-discutidos de perda de água constantes nos quadros 4 e 5 e nos hidrogramas da figura 2 e nos dados de perda de solo mostrados nos sedimentogramas da figura 3. Perdas de solo maiores em solo descoberto do que em tratamentos cobertos por diversas culturas foram verificadas também por Schäefer et al. (2001b), Leite et al. (2004) e Bertol et al. (2006).

A perda de água influenciou a perda de solo nos sistemas de manejo com cobertura sob as macieiras, o que é demonstrado pela relação entre razão de perda de solo (RPS) e razão de perda de água (RPA) (Figuras 4, 5 e 6). Nesses tratamentos, o modelo exponencial foi o que melhor ajustou-se a essa relação, em todos os casos ( $p>0,01)$. A RPS diminuiu ao longo do tempo de coleta de enxurrada, estabelecendo-se, nessa diminuição, dois momentos diferentes, distintos nos três tratamentos, enquanto a RPA aumentou continuamente ao longo desse tempo.

No tratamento ST (Figura 4), a RPS diminuiu de 0,42 para 0,05 , enquanto a RPA aumentou de 0,02 para 0,32 ; imediatamente após a RPA ter atingido o valor de 0,32 , a RPS aumentou para 0,15 , e voltou a diminuir para 0,05 quando a RPA aumentou para 0,80.

Quadro 6. Contraste de médias das perdas totais de solo no escoamento superficial, em sistemas de manejo do solo em pomar de maçã, sobre um Latossolo Bruno aluminoférrico típico, localizado na estação experimental da Embrapa Uva e Vinho de Vacaria

\begin{tabular}{crrrrrrr}
\hline \multirow{2}{*}{$\begin{array}{c}\text { Sistema } \\
\text { de manejo }\end{array}$} & \multicolumn{3}{c}{ Teste } & & \multicolumn{2}{c}{ Contraste } \\
\cline { 2 - 3 } & T1 & T2 & T3 & & T1 vs $\mathbf{~ ( T 2 , ~ T 3 ) ~}$ & T2 vs T3 \\
\hline SC & 2.116 & 893 & 978 & & $* *$ & $\mathrm{~ns}$ \\
ST & 158 & 69 & 58 & & $\mathrm{~ns}$ & $\mathrm{~ns}$ \\
AN & 194 & 61 & 46 & $\mathrm{~ns}$ & $\mathrm{~ns}$ \\
AD & 154 & 92 & 117 & $\mathrm{~ns}$ & $\mathrm{~ns}$
\end{tabular}

Contraste

$\mathrm{SC} v s(\mathrm{ST}, \mathrm{AN}, \mathrm{AD}) * * \quad * * \quad * *$

$\mathrm{ST}$ us $(\mathrm{AN}, \mathrm{AD}) \quad \mathrm{ns} \quad \mathrm{ns} \mathrm{ns}$

$\mathrm{AN}$ vs $\mathrm{AD} \quad \mathrm{ns} \quad \mathrm{ns} \quad \mathrm{ns}$

ST: sistema tradicional; $\mathrm{AN}$ : aveia não dessecada; $\mathrm{AD}$ : aveia dessecada; SC: solo sem cobertura; T1: teste 1; T2: teste 2; T3: teste 3 . Ns: não significativo pelo teste $\mathrm{F}$; **: significativo a $1 \%$ pelo teste $\mathrm{F}$. Interação entre manejo e teste significativa a $5 \%$.

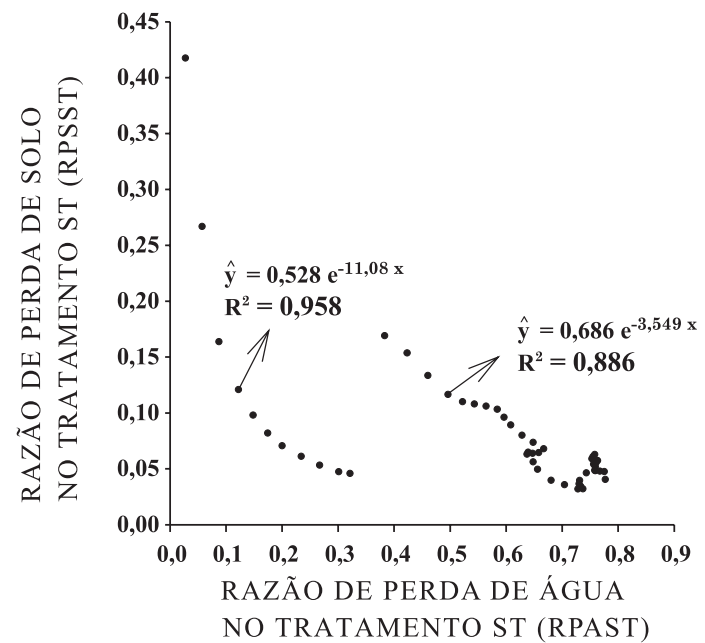

Figura 4. Relação entre a razão de perda de solo e a razão de perda de água no tratamento de manejo do solo ST em pomar de maçã, sobre um Latossolo Bruno aluminoférrico típico, localizado na estação experimental da Embrapa Uva e Vinho de Vacaria. (Média das repetições e dos testes de chuva).

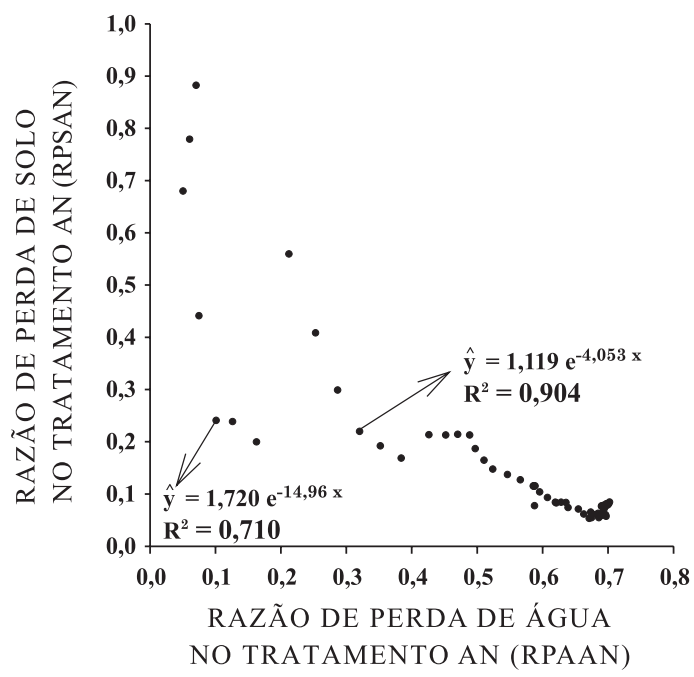

Figura 5. Relação entre a razão de perda de solo e a razão de perda de água no tratamento de manejo do solo AN em pomar de maçã, sobre um Latossolo Bruno aluminoférrico típico, localizado na estação experimental da Embrapa Uva e Vinho de Vacaria. (Média das repetições e dos testes de chuva).

Portanto, num primeiro momento, a RPS diminuiu $88 \%$ para um aumento de 16 vezes na RPA e, num segundo momento, após ter aumentado, a RPS diminuiu $66 \%$ para um aumento de 2,5 vezes na RPA. No tratamento AN (Figura 5), a RPS diminuiu de 0,90 para 0,20, enquanto a RPA aumentou de 0,02 para 0,16 ; imediatamente após a RPA ter atingido o valor de 0,16 , a RPS aumentou para 0,55 , e voltou a diminuir 


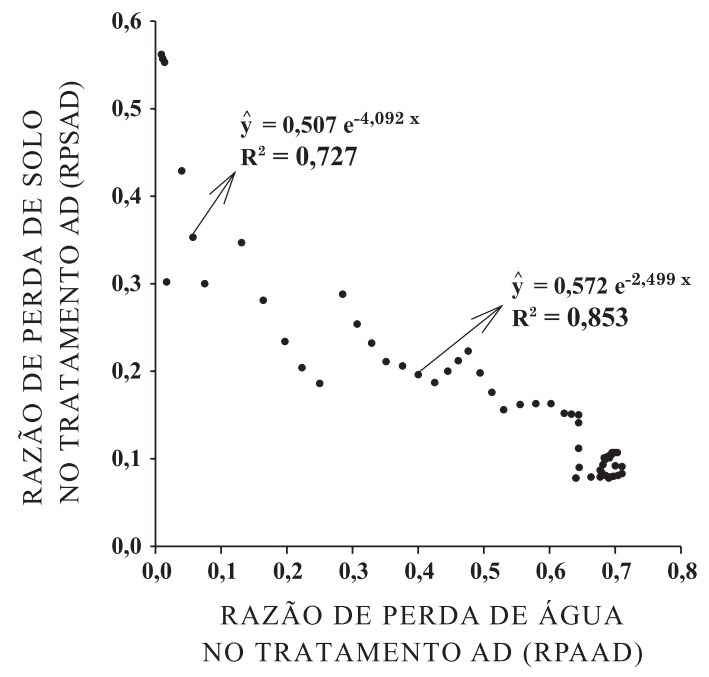

Figura 6. Relação entre a razão de perda de solo e a razão de perda de água no tratamento de manejo do solo AD em pomar de maçã, sobre um Latossolo Bruno aluminoférrico típico, localizado na estação experimental da Embrapa Uva e Vinho de Vacaria. (Média das repetições e dos testes de chuva).

para 0,05 quando a RPA aumentou para 0,70. Assim, num primeiro momento, a RPS diminuiu $78 \%$ para um aumento de oito vezes na RPA e, num segundo momento, após ter aumentado, a RPS diminuiu $91 \%$ para um aumento de 4,4 vezes na RPA. No tratamento AD (Figura 6), a RPS diminuiu de 0,56 para 0,18 , enquanto a RPA aumentou de 0,01 para 0,25; imediatamente após a RPA ter atingido o valor de 0,25 , a RPS aumentou para 0,30 , e voltou a diminuir para 0,08 quando a RPA aumentou para 0,72 . Portanto, num primeiro momento, a RPS diminuiu $68 \%$ para um aumento de 25 vezes na RPA e, num segundo momento, após ter aumentado, a RPS diminuiu $73 \%$ para um aumento de 2,9 vezes na RPA.

O comportamento dos dados das figuras 4,5 e 6 explica-se fisicamente. A quantidade de sedimentos disponíveis ao transporte pela enxurrada era relativamente alta no início do escoamento superficial em relação ao final: no tratamento $\mathrm{ST}$, devido à mobilização do solo sob as plantas de maçã; no tratamento $\mathrm{AN}$, em razão do preparo do solo com enxada manual para semeadura da aveia; e, no tratamento $\mathrm{AD}$, devido ao preparo do solo com enxada rotativa para semeadura da aveia. A quantidade de sedimentos no fluxo aumentou levemente até um máximo ao longo do escoamento (Figura 3), quando decresceu nesses tratamentos. No tratamento SC, o qual foi utilizado como comparativo com os demais para estabelecer a RPS, a quantidade de sedimentos no fluxo aumentou mais intensamente ao longo do escoamento do que nos tratamentos ST, AN e AD. Isso resultou na redução de RPS nos tratamentos ST, $\mathrm{AN}$ e $\mathrm{AD}$ até o momento do pico de sedimentos no fluxo no tratamento SC, decrescendo tal RPS a partir desse ponto. Portanto, o aumento da RPS em determinado momento do escoamento superficial, após ela ter diminuído ao longo da duração do escoamento, explica-se pelo fato de estar-se tratando, aqui, de uma relação de duas razões e, em especial, pelo fato de a RPS ter se modificado ao longo do tempo. Note-se que a RPA não se modificou ao longo do tempo de escoamento, pois em todos os tratamentos ela aumentou continuamente até o pico do escoamento superficial, estabilizando a partir desse momento (Figura 2).

\section{CONCLUSÕES}

1. A forma de manejo da superfície do solo e o número de chuvas influenciaram as perdas de solo e água por erosão hídrica em pomar de maçã, observando-se que as perdas de solo variaram amplamente e as perdas de água mostraram menor variação.

2. O cultivo de aveia com mobilização do solo em toda a área das parcelas apresentou a mesma eficácia no controle da erosão hídrica em relação à cobertura tradicional do solo composta de gramíneas e leguminosas, com mobilização do solo apenas sob a copa das plantas.

3. A eliminação da cobertura do solo sob as plantas de maçã influenciou fortemente a erosão hídrica no pomar; o efeito foi maior nas perdas de solo do que de água.

4. As perdas de água e solo foram influenciadas pela duração do escoamento superficial; as perdas de solo aumentaram até certo momento de ocorrência do escoamento e a partir daí diminuíram, ao passo que as perdas de água aumentaram até certo momento e a partir daí estabilizaram, independentemente do tipo e do sistema de manejo da cobertura do solo sob as plantas de maçã.

5. Houve relação inversa entre a razão de perda de solo e a razão de perda de água por escoamento superficial, independentemente do tipo e do sistema de manejo da cobertura do solo sob as plantas de maçã; um modelo exponencial ajustou-se bem aos dados dessa relação.

\section{LITERATURA CITADA}

ADAMS, J.E. \& ARKIN, G.F. A light interception method for measuring row crop ground cover. Soil Sci. Soc. Am. J., 41:789-792, 1977.

AGAPOMI. Levantamento de área de maçã no Rio Grande do Sul - 2007. Disponível em: <http://www.agapomi.com.br/ arquivos/area_municipio_2007.pdf>. Acesso em 02 de março de 2009 .

AMAP. Situação da Maçã em Santa Catarina. Disponível em: <http://www.amap-sc.com.br/>. Acesso em 03 de março de 2009 . 
ARRUDA, F.B. Determinação da cobertura do solo durante o ciclo das culturas. R. Bras. Ci. Solo, 8:145-150, 1984.

BERTOL, I.; BARBOSA, F.T.; FABIAN, E.L.; PEGORARO, R.; ZAVASCHI, E.; PAZ GONZÁLEZ, A. \& VIDAL VÁZQUEZ, E. Escoamento superficial em diferentes sistemas de manejo em um Nitossolo Háplico típico. R. Bras. Eng. Agr. Amb., 12:243-250, 2008.

BERTOL, I.; MELLO, E.L.; COGO, N.P.; VIDAL VÁZQUEZ, E. \& PAZ GONZÁLEZ, A. Parâmetros relacionados com a erosão hídrica sob taxa constante de enxurrada, em diferentes métodos de preparo do solo. R. Bras. Ci. Solo, 30:715-722, 2006.

BERTOL, I.; COGO, N.P. \& LEVIEN, R. Relações da erosão hídrica com métodos de preparo do solo, na ausência e na presença de cobertura por resíduo cultural de trigo. $\mathrm{R}$. Bras. Ci. Solo, 11:187-192, 1987.

CASSOL, E.A.; CANTALICE, J.R.B.; REICHERT, J.M. \& MONDARDO, A. Escoamento superficial e desagregação do solo em entressulcos em solo franco-argilo-arenoso com resíduos vegetais. Pesq. Agropec. Bras., 39:685-690, 2004.

COGO, N.P. Effect of residue cover, tillage induced roughness, and slope length on erosion and related parameters. West Lafayette, Purdue University, 1981. 346p. (Tese de Doutorado)

COGO, N.P.; MOLDENHAUER, W.C. \& FOSTER. G.R. Soil loss reductions from conservation tillage practices. Soil Sci. Soc. Am. J., 48:368-373, 1984.

CURCIO, G.R.; CARVALHO, A.P.; ROSSI, M.; ALMEIDA, J.A \& COELHO, M.R. Descrição de perfis do Estado do Rio Grande do Sul. Porto Alegre, 1999. 89p.

EMPRESA BRSILEIRA DE PESQUISA AGROPECUÁRIA . EMBRAPA. Centro Nacional de Pesquisa de Solos. Sistema brasileiro de classificação de solos. 2.ed. Rio de Janeiro, 2006. 306p.

FORSYTHE, W. Física de suelos: Manual de laboratório. San José, Instituto Interamericano de Ciências Agrícolas, 1975. $209 p$.

GOBBI, E. Erosão hídrica em pomar de maçã sob diversas formas de manejo do solo comparadas ao campo natural Lages, Universidade do Estado de Santa Catarina, 2009. 74p. (Tese de Mestrado)

HUDSON, N.W. Soil conservation. 3.ed. Ithaca, Cornell University Press, 1995. 324p.

KOHNKE, H. Soil physics. New York, McGraw - Hill, 1968. 224p.

KOSMAS, C.; DONALATOS, N.; CAMMERAAT, L.H.; CHABART, M.; DIAMANTOPOULOS, J.; FARAND, R.; GUTIERREZ, L.; JACOB, A.; MARQUES, H.; MARTINEZFERNANDEZ, J.; MIZARA, A.; MOUSTAKAS, N.; NICOLAU, J.M.; OLIVEROS, C.; PINNA, G.; PUDDU, R.; PUIGDEFABREGAS, J.; ROXO, M; SIMAO, A.; STAMOU, G.; TOMASI, N.; USAI, D. \& VACCA, A. The effect of land use on runoff and soil erosion rates under Mediterranean conditions. Catena, 29:45-59, 1997.

LEVIEN, R. Erosão na cultura do milho em diferentes sistemas de cultivo anterior e métodos de preparo do solo. Porto Alegre, Universidade Federal do Rio Grande do Sul, 1988. 168p. (Tese de Mestrado)
LEITE, D.; BERTOL, I.; GUADAGNIN, J.C.; SANTOS, E.J. \& RITTER, S.R. Erosão hídrica em um Nitossolo submetido a diferentes sistemas de manejo sob chuva simulada: I perdas de solo e água. R. Bras. Ci. Solo, 28:1033-1044, 2004.

LUCIANO, R.V.; BERTOL, I.; BARBOSA, F.T.; VIDAL VÁZQUEZ, E. \& FABIAN, E.L. Perdas de água e solo por erosão hídrica em duas direções de semeadura de aveia e ervilhaca. R. Bras. Ci. Solo, 33:669-676, 2009.

MARANGONI, B.; SCUDELLARI, D. \& TACLIAVINI, M. Relazione tra nutrizione azotata e metabolismo delle piante. R. Fruttic. Ortofloric., 58:7-8, 1995.

O'GEEN, A.T.; PRICHARD, T.L.; ELKIND, R. \& GROVE, G.S.P. Orchard floor management practices to reduce erosion and protect water quality. Berkeley, University of California, Division of Agriculture and Natural Resources, 2006. 9p. (ANR Publication, 8202)

PENTEADO JUNIOR, J.F.; MAY-DE-MIO, L.L.; MONTEIRO, L.B. \& GAYER NETO, W. Apropriação e análise de custo de implantação de pomar de pessegueiro. Sci. Agr., 9:117. 122,2008

RENARD, K.G.; FOSTER, G.R.; WEESIES, G.A.; McCOOL, D.K. \& YODER, D.C. Predicting soil erosion by water: A guide to conservation planning with the revised universal soil loss equation (RUSLE). Washington, U.S. Department of Agricultural, 1997. 384p. (Agriculture Handbook, 703)

SANCHEZ, L.A.; MICHELE, A. \& LÓPEZ, R. Soil erosion under different vegetation covers in the Venezuelan Andes. Environmentalist, 22:161-172, 2002.

SCHÄEFER, M.J.; REICHERT, J.M.; CASSOL, E.A.; ELTZ, F.L.F. \& REINERT, D.J. Erosão em sulcos em diferentes preparos e estados de consolidação do solo. R. Bras. Ci. Solo, 25:419-430, 2001a.

SCHÄEFER, M.J.; REICHERT, J.M.; REINERT, D.J. \& CASSOL, E.A. Erosão em entressulcos em diferentes preparos e estados de consolidação do solo. R. Bras. Ci. Solo, 25:431-441, 2001b.

SHARPLEY, A.N.; SMITH, S.J. \& NANEY, J.W. Environmental impact of agricultural nitrogen phosphorus use. Madison, American Chemical Society, 1987. $11 \mathrm{p}$

SCHWAB, G.O.; FANGMEIER, D.D.; ELLIOT, W.J. \& FREVERT, R.K. Soil and water conservation engineering. 4.ed. New York, John Wiley \& Sons, 1993. $507 p$.

SWANSON, N.P. A rotating-boom rainfall simulator. Trans. Am. Soc. Agric. Eng., 8:71-72, 1965.

VIEIRA, M.L. \& KLEIN, V.A. Propriedades físico-hídricas de um Latossolo Vermelho submetido a diferentes sistemas de manejo. R. Bras. Ci. Solo, 31:1271-1280, 2007.

VOORHEES, W.B. \& LINDSTROM, M.J. Long-term effects of tillage method on soil tilt independent of wheel traffic compaction. Soil Sci. Soc. Am. J., 48:152-156, 1984.

WISCHMEIER, W.H. \& SMITH, D.D. Predicting rainfall erosion losses: A guide to conservation planning. Washington, USDA, 1978. 58p. (Agricultural Handbook, 537) 